\title{
Four-in-One Educational Quality Security System on Majors in Economics or Management for Those Foreign Students in China
}

\author{
Hongbing You \\ School of Economics \& Management \\ Nanjing University of Science \& Technology, NJUST \\ Nanjing, P.R. China
}

\author{
Xue Gong \\ School of Economics \& Management, \\ Nanjing University of Science \& Technology, NJUST \\ Nanjing, P.R. China
}

\author{
Weifan Wang \\ School of Economics \& Management, \\ Nanjing University of Science \& Technology, NJUST \\ Nanjing, P.R. China
}

Then how to cultivate such qualified talents? Based on our long-term experience in cultivating foreign students of majored in Economics and Management in China, we think the following four measures are fundamental to ensuring the teaching quality of those majors both in Economics and Management for foreign students in China.

\section{ESTABLISHING A STRICT SELECTION SYSTEM TO CONTROL THE ENROLLMENT QUALITY}

Based on years of teaching experiences, we found that there are two important factors, one is the linguistic ability and the other is the mathematical knowledge, which constraint the learning of foreign students in China although strict selection system in aspects of country and school is put in place to ensure admission quality of foreign students majored in Economics and Management in China.

The communication tool is language. Good linguistic ability is beneficial for those learners to acquire and grasp knowledge and apply the knowledge to analyzing and solving problems. Nowadays, foreign students in China are mainly taught in Chinese or English. Although their linguistic ability can be evaluated by the language proficiency certificates they submit(such as the HSK, the TOEFL or the IELTS), the certificates don't equal to their practical ability of language.

Since 1997, some students from the Philippines, Malaysia and other countries have entered into our university to participate in the undergraduate program of International Economy and Trade. Up to now, it has been more than 20 years since our university was open to foreign students. Among them, foreign students majored in Economics and Management include undergraduates, masters, and doctors, totaling about 200. In the process of teaching and guiding postgraduate students, as well as in the exchange with counterparts of colleges and universities in Nanjing, we have found that practical ability of language has been the biggest obstacle for a small number of students to grasp knowledge. 
Compared with those students major in science or engineering, those students major in economics or the management have fewer requirements for mathematical knowledge. But experience shows that a good mathematical foundation is an important factor to learn economics or the management well, and mathematics can also help to improve the people's ability for logical thinking and judgment. Therefore, it is necessary to offer courses like higher mathematics in the talent cultivation plan. However, teachers unanimously reflect that some students have poor mathematics foundation, which leads to two negative effects. First, it slows the teaching of the course and makes it impossible for those students of better mathematical foundation to fully learn knowledge because of the limitation of course time. Second, a small number of students of poor mathematics foundation can't learn mathematics well or lose their learning confidence, which, as for undergraduates, will affect their follow-up courses based on mathematics and, as for those master students, will affect their study in the period of master's thesis to a large extent, especially the quality of their graduation dissertation.[2]

Firstly, applicants' linguistic ability should be evaluated in an all-around way. For those Top 15 countries from where the foreign students came to China in 2018, there are 278,739 students, accounting for $56.63 \%$ of the total students. The USA is the only country of these 15 countries whose mother language is English. However, students from the USA are just 20,996 students, which accounts for only $4.26 \%$. For those students from the other 14 countries outside the United States, English is a kind of foreign language, and some even a second foreign language. As we know, only China and Singapore use Chinese as the official language in the world. However, Singapore is not among the list of the Top 15 countries mentioned above. In other words, Chinese is a kind of foreign language for all students in the Top 15 countries mentioned-above. Therefore, whether they were taught in Chinese or in English, more than 95\% of the students would have been to be educated in the non-native language. Although all foreign students who are applying to study in China are required to provide language proficiency certificate of Chinese or English when applying, the phenomenon of "dumb language" still exists, to a certain extent, while the proportion of students who are proficient in non-native language teaching is very small[3].

Secondly, mathematical ability should be a prerequisite of learning in majors of Economics and Management in China. Applicants should take tests organized by entrusted institutions of relevant countries to evaluate their mathematical knowledge and ability, and passing the test should be the prerequisite of selection.

\section{MAKing The Personnel Training Program SCIENTIFICALLY TO REALIZE THE EDUCATIONAL} OBJECTIVE

For foreign students of major in economics or the management in China, learning in China(master and doctor stage included) provides them with an opportunity to focus on learning and systematically learn the knowledge of economics and management, especially the Chinese culture and China's advanced management philosophy and methods. Besides, they are ambassadors of cultural exchange. Thus the cultivation plan for foreign students majored in economics or management in China should meet their needs to systematically learn the knowledge of economics and/or management and also pay attention to their roles as ambassadors of cultural exchange.

Therefore, it is important to draw up and optimize the talent cultivation plan based on the principle of precision and accuracy for foreign students of major in economics or management in China. Concretely speaking, considering some colleges and universities' practice of the talent cultivation plan for undergraduates and postgraduates of major in economics or management and the feedbacks of foreign students in China, we think it can start from the following two aspects to make the cultivation plan precise and accurate.

Firstly, it is advisable to offer fewer but better courses. For foreign students who attend lessons given in Chinese, they should be taught by the cultivation plan for Chinese students except for that political courses can be omitted from their curriculum. However, in this paper, the author studies the cultivation plan for foreign undergraduates and postgraduates of major in economics or management in China who are taught in all English. The mother tongue of most foreign students isn't English, neither is that of teachers of mainland colleges and universities that teach students in all English. It's not an easy thing to give lessons and communicate with a foreign language. What may make it more difficult is the inaccurate pronunciation, students' unfamiliarity with professional English vocabulary and other factors. Thus, it's difficult for teachers to give lessons through non-native language and for students to accept education through non-native language, especially when it comes to professional knowledge. Of course, there are relevantly more and more returned teachers who are proficient in teaching in English in mainland colleges and universities. For some students, English is one of their mother tongues, and some students have the experience of studying in English-speaking countries. However, neither all teachers nor the students are in the same case. The uneven English proficiency determines that it takes more time to teach and learn through non-native language than to teach and learn through the native one. Students need more time to understand, fully grasp and flexibly apply knowledge taught in a non-native language. And as part of college talent cultivation system, many courses in whether undergraduate or postgraduate stage are interconnected. For example, macroeconomics is the preparatory course for the courses of finance, international trade, international economics, and other courses and lays the foundation for the learning of the later courses. Once a preparatory course is not learned well, it's difficult to learn its follow-up courses well, which will affect the study of all courses, and eventually make a small number of students fail to graduate on schedule.

Considering those mentioned above, it is advisable to adhere to the principle of "two lesser, two more" in deciding the number of courses of foreign students in China. "Two lesser" means reducing the total required credits for graduation and the number of courses in moderation and "two more" means increasing in moderation the credits of professional core courses and preparatory courses and the class time for 
explaining key knowledge, theories and methods. The "two lesser" measure is designed to realize the "two more" measure better. The "two lesser, two more" principle can eventually make the talent cultivation plan and teaching more precise and accurate.

Secondly, it is advisable to increase courses with Chinese characteristics in moderation. Wherever foreign students in China work in the future, they are the ambassador of cultural exchange between China and their countries. To make them become a qualified ambassador, the key lies in making them understand and grasp more Chinese characteristics. Experience shows that Chinese, Chinese martial arts, Chinese management, Chinese economy, and Chinese history are of great significance in helping foreign students to better understand China and conduct political, economic and cultural exchanges with China easily after graduation. In the education for foreign students in China, Nanjing University of Science \& Technology offers such courses as Introduction to Chinese, Taijiquan, Overview of China, and Chinese History and Culture, which are popular with the foreign students. Besides, NJUST offers the course of Overview of China's Opening to the Outside World for foreign students of Economics and Management, and add an introduction to the knowledge about the management of Chinese enterprises in the course of Principles of Management. In 2017, a few students major in international economics and trade have chosen to work or continue their study in China. We also found that in 2018 more than 50 graduating students of Economics and Management from Asia, Africa, and Latin America had similar dreams with graduating students in 2017. Many of them come from countries along the "Belt and Road Initiative" route. Through studying in China, they learn more Chinese elements, which will be of great significance to their development and help their families, friends and even their countries better understand China's development model of peace, development, openness, cooperation, harmony, and win-win.

\section{STRENGTHENING THE ClAsSROOM TEACHING}

Management to Guarantee the Cultivation Process

Even a perfect teaching plan can negatively affect the quality of talent cultivation when it can't be put into practice well or fully[4]. So does the cultivation plan for foreign students of Economics and Management in China. Foreign students in China constitute a group of diverse culture, with a different way in understanding and uneven basic education. These bring obstacles to the implementation of the teaching management system. For instance, a small number of students with poor time concept are often late for school and absent from school without leave or ask for leave with cold or rainy days as excuses. Some students even can't understand the teaching modes of some teachers. Even though, they still expect that teachers can give them good grades in final exams. However, different teachers have different standards in grading. Sometimes, a teacher has to choose loose standards for special reasons, which becomes an excuse for a few students to expect other teachers also use loose standards.

Base on previous experience, we think the following measures should be taken in the teaching of foreign students of Economics and Management in China.
Firstly, it's advised to set strict class discipline. Experience shows that although students from different countries have different time concepts (sometimes of huge difference), some lazy students or students with poor time concept can be punctual in class and finish their homework earnestly if their teachers let students know the school discipline and strictly enforce it, like ineligibility to take final exams when the student is absent from class for one third of the total course hours or more. If teachers don't prevent such bad behaviors, the course can become a total failure. In particular, in light of the characteristics of thoese majors in Economics and Management, we deliberately emphasize the importance of punctuality and following rules through cases analysis and role play in the teaching of relevant courses. In recent years, teachers have reflected that discipline in class is going better. Strict discipline can help a student learn knowledge in a more all-around way and better develop the habit of following rules.

Secondly, it's advisable to establish a comprehensive teaching management system that needs joint efforts of the educational administration department, the teaching unit, counselors and teachers to ensure the quality of teaching. Although teachers have more direct control and influence in the specific teaching, good talent cultivation quality needs joint efforts of all relevant departments to cultivate talents in an all-round way, which teachers obviously can't do alone. It is necessary for the educational administration department, teaching unit, counselors and teachers of colleges and universities to cooperate and form a comprehensive teaching management system. Concretely speaking, as for the educational administration department, it should set formal Chinese and English version of management system targeted for foreign students to provides rules to follow for relevant departments. In drawing up rules and regulations for foreign students, it is not feasible to simply translate the existing management system for Chinese students into English and implement convergent management. As for teaching units, they should remind teachers to strictly enforce the teaching rules and regulations. As for counselors, they should provide more targeted guidance according to the characteristics of foreign students to solve their problems in their study on time. As for teachers, they should strictly enforce discipline and make teaching proceed by the rules and regulations. Particularly, the educational administrative staff of the teaching institute and the counselors for foreign students should have a good command of English to avoid their existing in name only.

\section{ESTABLISHING PERFECT INTERNSHIP EDUCATION SySTEM TO GUARANTEE THE THEORIES TO BE WELL APPLIED}

The number of foreign students in China keeps increasing in recent years, and many of them learn in the college of Economics and Management. But in the process of cultivating Economic and Management talents, more attention is paid to theoretical teaching while practical teaching is weak as a result of language barrier and difficulty to find internship in China because in the present there are almost no institutes that provide them with work with their mother tongue as working language, and few companies use English as the main working language, in addition to some companies' caution against 
giving away business secrets. But practical teaching is an important and indispensable part in talent cultivation. Therefore, it's advised to start from the three following aspects to ensure practical teaching.

Firstly, it's advised to construct more emulation internship platforms[5]. At present, with the development of educational internationalization and for the need of all English teaching in colleges and universities in China, some domestic software development organizations develop virtual simulation software with English as the working language, such as Cross-border E-commerce and ERP software. With conditions permitted, colleges and universities can choose and purchase some software with English as the working language. They can also make use of the existing Chinese software and make Chinese students and foreign students practice in pair to increase opportunities for Chinese students to use English, and to achieve the effect of practice for foreign students in China, which promotes the effective utilization of the existing software to the maximum.

Secondly, it's advisable to find internship bases for foreign students in China if conditions permit. At present, a large proportion of the foreign students in China come from countries along the "Belt and Road Initiative" route. Since the implementation of the "Belt and Road Initiative" initiative, more and more enterprises in mainland China have either expanded the scale of economic and trade exchanges with countries along the "Belt and Road Initiative" route or have begun to expand their markets in this region[6]. Under this circumstance, it would achieve perfect effect if there is a team that understands both Chinese culture and the local culture and policies and likes to serve Chinese enterprises. In the summer of 2017, a refrigeration machinery enterprise in Nanjing found that there were Vietnamese students in our school and offered to provide them with opportunities to take an internship in its company. Both sides expressed strong interest after bilateral communication. There are no few such enterprises near colleges and universities, so the relevant employment departments or teachers in colleges and universities should actively seek and find out such internship opportunities for foreign students. After all, this is also an important way to ensure the quality of talent cultivation[7].

Thirdly, it's advisable to establish a mechanism for allowing students to return to their countries for an internship. Since most foreign students in China need to work in their own countries after graduation, thus allowing them to take an internship in their own countries after theoretical learning is also an important measure to ensure the quality of talent cultivation.

\section{CONCLUSIONS}

With the promotion of the One Belt and One Road initiative, more and more foreign students are packed into China to continue their studies. The scientific talent training system is of great significance not only to enhance the attraction of Chinese education to foreign students but also to realize the dream of foreign students to study in China. It is believed that the above-mentioned suggestions can play a certain role in ensuring the quality of education for overseas students in China.

\section{ACKNOWLEDGMENT}

The paper is supported by the Project of National Natural Science Foundation of China: OFDI-Driven Education for Foreign Students in China: Research on Influencing Mechanism, Structural Layout and Development Path (Project No. 71704079) and Curriculum Project for Graduate Students "Intermediate International Trade: Theory and Practice" (S107B071) by Graduate School at NJUST in 2019

\section{REFERENCES}

[1] Bocean Claudiu George \& Popescu Daniela Victoria \& Logof Äftu Monica, "Quality in Education - Approaches and Frameworks," Ovidius University Annals, Economic Sciences Series, Ovidius University of Constantza, Faculty of Economic Sciences, vol. 0(2), pp199-204, December 2018.

[2] Huang Guifang, "Thoughts on strengthing the management of education for foreign students of colleges and universities in China”[J] . Journal of Higher Education,vol.37, pp.19-30, July 2016. (In Chinese)

[3] Song Weihong, "Problems and countermeasures of universities foreign students education management”. Journal of Higher Education, vol.34, pp. 38-42, June 2013.

[4] Marina Bassi \& Costas Meghir \& Ana Reynoso, 2016. "Education Quality and Teaching Practices," NBER Working Papers 22719, National Bureau of Economic Research, Inc.

[5] You Hongbing, "Six-pronged approach to promoting the cultivation of international talents”. Jiangsu Higher Education, pp.101-102, June 2014.

[6] Zheng Gang, Ma Le. "The Belt and Road strategy and education of foreign students in China: Based on the data from 2004 to 2014". Education \& Economy, pp.77-82, April 2016.

[7] Liu Jinlan, Li Yong, Wu Aifeng. Being open and inclusive, promoting the employment of outstanding foreign students in China[J] . China Higher Education, vol. Z3,pp.54-56. 2015. (In Chinese) 